\title{
LA FILOSOFÍA Y LOS DISCURSOS RELIGIOSOS
}

\author{
Carmenza Neira F. \\ Universidad Santo Tomás
}

\section{Resumen}

El grupo de investigación Antón de Montesinos de la Facultad de Filosofía de la Universidad Santo Tomás de Bogotá es un equipo de investigadores que busca fundamentar teóricamente y experimentar en la práctica el ejercicio de la reflexión y el discurso interdisciplinarios. Esta conferencia ha sido uno de los resultados de este ejercicio de investigación, en el cual, desde una perspectiva filosófica y utilizando categorías como las de juego del lenguaje, imagen, forma de vida y gramática profunda, se analiza un discurso religioso y pastoral, el de los Obispos de América Latina en su última Asamblea General en Santo Domingo. Es un avance de la investigación en la línea Lenguajes simbólicos y discursos fronterizos. Se entiende como discurso fronterizo aquel que requiere del enfoque de diversas ciencias humanas.

\section{Palabras clave}

Filosofía, juegos del lenguaje, discurso religioso, lenguaje simbólico, discurso fronterizo.

\section{Abstract}

Antón de Montesinos, the Research team from the philosophy school at Santo Tomás University in Bogotá, is a group of researchers who seek for theoretical foundations and get experience from the practical reflexion and the interdisciplinary discourse. This lecture has been one of the results from this research exercise, which, from a philosophical perpective and using categories such as the ones from languages games, image, life style and deep grammar, the religious and pastoral discourse, the one that the LatinAmerican Bishops held at their last General Assembly in Santo Domingo, is analized. This is a research break through concerning Symbolic languages and bordering discourses. Specifically, bordering discourse means the one which requires the approach of different humanistic sciences. 


\section{Index terms}

Philosophy, language games, religious discourse, symbolic language, bordering discourse.

Llama la atención la distancia que percibimos entre los discursos religiosos de los apologistas, los teólogos y algunos predicadores, y la forma que tienen de comprender y vivir la fe cristiana la mayoría de las personas en nuestros contextos latinoamericanos.

Si la misión de la Iglesia de Cristo es la de ir y predicar el Evangelio a todas las gentes, ¿en qué consistirá el que sus mensajes hayan sido poco comprendidos entre el común de nuestros pueblos? ¿Cuál podrá ser la responsabilidad de la universidad católica y aún más de las facultades de filosofía ante este fenómeno?

Estos interrogantes han sido el motivo por el cual hemos elegido como horizonte de reflexión "la filosofía y los discursos religiosos”, título muy amplio para el trabajo de análisis y reflexión que intentamos hacer.

En la relación religión-filosofía encontramos, desde los antiguos griegos, una especie de oposición, como si el logos fuera incompatible con las religiones mistéricas, el antropomorfismo de la mitología, el chamanismo y la magia.

La crítica de Jenófanes al politeísmo es una muestra significativa. "Por un lado, Jenófanes ridiculiza la tendencia general de los hombres a representarse a los dioses con características corpóreas humanas y la costumbre de cada pueblo en particular de configurarlos con los caracteres somáticos propios de su raza. 'Los mortales creen que los dioses tienen vestiduras, voces y cuerpos similares a los de ellos. (...) Y los etíopes representan a sus dioses chatos y negros y los tracios dicen que tienen ojos azules y cabellos rubios. (...) Pero si los bueyes, los caballos y los leones tuvieran manos y con ellas pudieran dibujar o realizar obras como los hombres, los caballos dibujarían figuras de dioses semejantes a los caballos, y los bueyes a los bueyes y formarían su cuerpo a imitación del propio", ${ }^{\text {. }}$.

Por otra parte, ha existido también entre los filósofos el reto por dar razón, desde la filosofía, de esa dimensión humana que se abre al infinito. Como afirma Heráclito: “Aún siendo este Logos real, siempre se muestran los hombres incapaces de comprenderlo (...)”2.

El impacto del Evangelio en los primeros cristianos puso a los creyentes, judíos o no, filósofos o no, en el predicamento de dar razón de su fe ante sus contemporáneos. Dar la Buena Nueva fue muy difícil. Una nueva que era “locura” para los gentiles y “escándalo para los judíos”. Las apasionadas reflexiones de los primeros Padres de la Iglesia y de los Apologistas nos muestran no sólo una fe racionalmente aceptada, sino apasionadamente vivida.

Pero, con el fortalecimiento político del cristianismo después de Constantino, el reto no consistió solamente en dar razón de la fe, en convencer a los no creyentes, sino en proteger el kerigma cristiano de las contamina-

\footnotetext{
1 MONDOLFO, Rodolfo. La comprensión del sujeto humano en la cultura antigua. Buenos Aires: Eudeba, 1968, p. 49.

2 Ibíd., p. 30.
} 
ciones del poder temporal. Desde Boecio hasta el Renacimiento las relaciones filosofía-teología, Iglesia y poderes temporales fueron estrechas y se justificaron en el tema de las relaciones entre fe y razón. Sin embargo la historia nos muestra que las relaciones entre Iglesia y poderes temporales sí se contaminaron con las ansias de poder. Esta contaminación y la relajación en las costumbres llevaron en el Renacimiento a la división de la cual surgieron las iglesias protestantes. El Concilio de Trento muestra un acto de contrición ante esas fallas morales y busca fortalecer tanto los contenidos de la fe católica como las exigencias de la praxis, de la ética cristiana. Coincidió con la etapa histórica de la conquista y colonización de las tierras americanas y, sin buscarlo, fue también instrumento del poder y de la dominación. La evangelización se vio oscurecida en parte por la sombra de la idea del "Orbe cristiano", que contiene soterradas muchas ideas de dominación. Sin embargo, gracias a los misioneros que predicaron con su vida y su convicción el Evangelio y respetaron como hermanos a los indígenas y a los negros del nuevo continente, se logró la discusión teórica en Salamanca, que dio origen al derecho de gentes y nos reconoció la categoría de humanos.

El Concilio Vaticano II soltó las amarras de Trento y logró crear un ambiente nuevo para el diálogo entre las religiones caracterizado por el respeto a las diversas culturas y por un nuevo tono del discurso, que más que insistir en los dogmas formulados insistió en esa presencia viva, en ese kerigma humilde y hecho praxis en la Iglesia como signo de los nuevos tiempos.

La filosofía en el siglo XX, al fijar su atención en los discursos religiosos, ha analiza- do y criticado severamente los intentos de predicar la fe desde argumentos racionales y "la inquietud occidental por encontrar una base metafísica que se constituya como fundante de lo real y le dé sentido" ${ }^{33}$. Son críticas desde la perspectiva epistemológica y que desde la fe se califican de teísmo, ateísmo o agnosticismo, según el caso. Podemos recordar a Bertrand Russell en su debate con Copleston, a Hans Albert en su debate con Hans Küng, o al mismo Wittgenstein en su Tractatus, en el que afirma que el lenguaje sí puede dar cuenta de la estructura interna de la realidad. El lenguaje actúa como un espejo de la realidad, pero hay elementos que están más allá, la ética, la religión y el arte. No es que el tema de Dios carezca de sentido, sólo que la razón y el lenguaje tienen sus límites, de manera que la religión hace parte de lo que no se puede decir. Dios no puede expresarse a través del lenguaje y la religión sería un territorio más próximo a la mística que a la filosofía.

Es de todos conocido que los Obispos de Latinoamérica desde 1955 se han reunido cuatro veces para poner en común los retos y respuestas que implica su acción pastoral en el Continente. Después del Concilio Vaticano II, las conferencias de Medellín en 1968, Puebla en 1979 y Santo Domingo, en 1992, buscaron diversas formas de acercarse con una nueva evangelización a las gentes de una Latinoamérica cambiante y cada vez más problemática.

En la IV Conferencia de Santo Domingo en 1992 (después de ésta no ha habido más) se reitera el problema de la Nueva Evangelización, pero en el marco de buscar una promoción humana inculturada. El ejercicio que pretendemos realizar consiste en hacer una nueva lectura e interpretación del Documen-

3 RODRÍGUEZ, Carolina. "Epistemología y lenguaje como expresiones de ateísmo”. En: Ponencias del IX Congreso internacional de filosofía latinoamericana. Bogotá: USTA, 2001, p. 232. 
to de Santo Domingo del CELAM, buscando analizar este texto como juego del lenguaje, y privilegiando en ello las categorías de imagen, forma de vida y gramática profunda del segundo Wittgenstein ${ }^{4}$.

Encontramos que el Documento expresa no solamente el kerigma, sino su encarnación en las formas de vida y diversas culturas que se reconocen hoy en el mundo; expresa también el valor de la fe y del testimonio, más que el de la belleza retórica de los sermones, o la fuerza coactiva del dogma, o los argumentos racionales para convencer a intelectuales. Es en la fe vivida, el compromiso en la praxis, en la forma de vida de cada cultura, donde tiene sentido el kerigma del Evangelio.

Al considerar el discurso religioso de los Obispos Latinoamericanos como juego del lenguaje, lo tratamos como una "praxis pública" ${ }^{5}$, una profesión de fe, consecuencia de una experiencia mística ${ }^{6}$. Según Wittgenstein, "hay ciertamente lo inexpresable, lo que se muestra a sí mismo; esto es lo místico"”.

Insistimos en que el ubicar el análisis del Documento dentro de la noción de juego del lenguaje significa considerarlo como un juego con sus reglas, propósitos, tradiciones y límites dentro de una determinada forma de vida. Supone también asumir la "creencia religiosa" como un juego de lenguaje, diferente al de la ciencia, generador de formas de vida, o sea "relacionado con problemas de orden práctico, visiones del mundo, intereses, etc." ${ }^{8}$.

Barret afirma que para comprender una creencia religiosa hay que compartirla ${ }^{9}$, lo que nos permite ubicar como destinatarios de este mensaje a todos los cristianos que comparten la creencia en Cristo resucitado. Y añade, en un párrafo, la relación del uso de la imagen con la creencia religiosa, reconociendo que en el caso de la imagen sí es posible una verificación, cuando se puede relacionar la imagen con las consecuencias o conclusiones prácticas que extrae el usuario de ella. Es decir, en nuestro caso, se trataría de relacionar la imagen con las actitudes y los cambios de sentimientos y conductas, tanto de los que emiten el mensaje como de los que lo reciben y hacen propio.

Estas nociones nos permiten destacar algunas imágenes evangélicas presentes en el texto, imágenes que consideramos como del lenguaje ordinario, puesto que la mayoría de las personas latinoamericanas las tenemos como acervo propio de nuestra cultura e incluso todavía las utilizamos, aunque no siempre con la conciencia de su origen evangélico.

A continuación vamos a presentar la estructura global del Documento, y en un segundo momento identificaremos algunas de las imágenes, de tal manera que sea posible relacionarlas con las descripciones del contexto y situación latinoamericanos, para mostrar que las claves de comprensión del texto están

$4 \quad$ Agradezco a Jean Greish y al P. Vicente Durán, S.I, por sus respectivos artículos, los cuales nos han ayudado en el acercamiento a la comprensión del segundo Wittgenstein.

5 Si no fuera pública, no podríamos considerarla como juego del lenguaje. BARRET, Cyril. Ética y creencia religiosa en Wittgenstein. Madrid: Alianza Universidad, 1994, p. 233.

$6 \quad$ Entendiendo místico en el sentido de asombrarse de que exista lo que existe. Ibíd., p. 224.

7 WITTGENSTEIN, Ludwig. Tractatus logico-philosophicus. Madrid: Alianza, 1973, p. 6522.

8 DURÁN, Vicente. "Lenguaje religioso y experiencia religiosa en Wittgenstein: ¿Un nuevo enfoque para la filosofía de la religión en América Latina?”. En: Problemas de filosofía de la religión desde América Latina. Bogotá: Siglo del Hombre, 2004, p. 235.

9 BARRET, Cyril. Ética y creencia religiosa en Wittgenstein. Op. Cit., p. 227. 
dadas por las situaciones descritas, la fe hecha vida de los Obispos y el contexto de la Buena Nueva del Evangelio.

“Una visión global del Documento permite percibir mejor la coherencia interna del proyecto pastoral, como totalidad y ubicar cada elemento en su relación orgánica con los demás” ${ }^{10}$. El Documento está estructurado relacionando varios temas, todos centrados en la Profesión de Fe en Jesucristo: Jesucristo, vida y esperanza de América Latina y del Caribe; Jesucristo, Evangelio del Padre; y Jesucristo, evangelizador viviente en su Iglesia.

Nuestra fe confiesa a Jesucristo ayer, hoy y siempre. Al asumir esta confesión como lema, la IV Conferencia funda el horizonte último de su proyecto pastoral en Jesucristo como Evangelio del Padre, como Buena Nueva, asequible sólo por la fe. De ahí la forma proclamatoria de Profesión de Fe del Documento. Jesucristo sigue viviendo y evangelizando en su Iglesia, y por esto es la vida y esperanza de América Latina y del Caribe. Sólo Jesucristo es promesa de vida para las situaciones trágicas de injusticia y sufrimiento de nuestra América.

Con este impulso en la fe, los Obispos trazan tres líneas prioritarias para la Pastoral:

1. La nueva evangelización desde las comunidades vivas.
2. La promoción humana integral de los pueblos latinoamericanos, en opción preferencial por los pobres, que promueva un nuevo orden económico, social y político en justicia, solidaridad, en defensa y promoción de la vida y de la familia.

3. Una evangelización inculturada que afronte los problemas de las grandes ciudades y su repercusión en las áreas rurales; que promueva la vitalidad del Evangelio, encarnándolo en las culturas indígenas y afroamericanas, y que asuma los desafíos de la cultura moderna ${ }^{11}$.

La primera parte, que se refiere a la nueva evangelización, es la que más imágenes nos proporciona, todas sacadas del Evangelio o de los Hechos de los Apóstoles. Ante todo, salta a nuestra vista la imagen de Jesucristo, ayer, hoy y siempre, que como un Pantocrátor llena con su presencia el interior del templo y lo ilumina con diversos visos y colores que fortalecen la fe. Esta imagen está reforzada ${ }^{12}$ con la de Jesucristo resucitado y cercano, como nos lo muestra en el Evangelio el camino de Emaús. Es Jesucristo resucitado, compañero de viaje, el que conoce nuestras depresiones y desconciertos, y el que con su conversación y actitudes enciende nuestros corazones. El sentido de esta imagen puede ser descrito como experiencia religiosa: "Confesamos que Jesús, que verdaderamente resucitó para comunicarnos la vida que es

10 NEIRA, Germán y DE ROUX, Rodolfo Eduardo. Renovación y proyección de la Iglesia, Documento de Santo Domingo, claves de lectura. Bogotá: Centro Javeriano, 1998, p. 21. Las observaciones de los Padres Rodolfo Eduardo de Roux, S.I., y Germán Neira, S.I., en su presentación de las claves de lectura para el Documento de Santo Domingo también nos han ayudado mucho para la comprensión del texto, de tal manera que utilizaremos aquí la síntesis que ellos nos aportan.

11 Ibíd., pp. 21-26.

12 Carlos Bousoño, en su Teoría de la expresión poética (Vol.1, Madrid: Gredos, 1970, pp. 140-173), propone como nueva categoría para el análisis del lenguaje poético la de imagen visionaria, diferente de las visiones, las metáforas y los símbolos. Estas imágenes visionarias se caracterizan sobre todo porque al superponerse unas a otras como si fueran transparentes, nos dejan percibir emocionalmente un mayor sentido del que expresaría aislada la imagen tradicional. En el Documento de Santo Domingo hemos encontrado una gran variedad de imágenes que dan más densidad a la anterior y por este uso casi nos atreveríamos a calificarlas de imágenes visionarias. 
nuestra esperanza, ya que puede salvar a los que se le acercan y está siempre vivo para interceder por nosotros (...) Sí, confesamos que, Jesucristo es verdaderamente hombre. Él es el hijo único del Padre, hecho hombre en el seno de la Virgen María, por obra del Espíritu Santo, que vino al mundo para librarnos de toda esclavitud de pecado, a darnos la gracia de la adopción filial y a reconciliarnos con Dios y con los hombres. Él es el Evangelio viviente del amor del Padre. En Él la humanidad tiene la medida de su dignidad y el sentido de su desarrollo" ${ }^{13}$.

A estas imágenes de Jesucristo resucitado se superpone también la del Cuerpo Místico de Cristo, referida a la Iglesia y abierta a mayor simbolismo cuando se la relaciona con la imagen de un Niño Dios Encarnado Misteriosamente en el Seno de María y la de María, Estrella que Guía la Evangelización.

Michel de Certeau, S.I., da a esta imagen dimensiones nuevas, cuando afirma que se instituyó sobre la pérdida del cuerpo de Jesús. En la última cena, Jesús dijo "este es mi cuerpo”, y ante la tumba de Jesús, María Magdalena gritó: “se lo han llevado y no sé dónde lo han puesto”. De ser la presencia de Dios en Jesús, la presencia de Jesús en el Pan y el Vino consagrados, pasa a ser la expresión de la ausencia de Jesús que se hace sensible como presencia en la construcción de su Iglesia. Según Certeau, “después de la mitad del siglo XII la expresión cuerpo de Cristo ya no designa a la Eucaristía sino a su Iglesia. La Iglesia cuerpo social de Cristo es el significado oculto de un cuerpo sacramental tenido como significante visible porque es la ostensión de una presencia bajo apariencias de pan y vino consagra- dos”14. Así, Cuerpo Místico alude a “un caminar que va, como toda peregrinación, hacia un sitio marcado por una desaparición”15.

Encarnación y Resurrección, presencia y ausencia, se fortalecen mutuamente y dan sentido a la comunidad de creyentes como Cuerpo de Cristo. De esta manera, la imagen cobra mayor énfasis al contraponerla a otra, El rostro desfigurado del mundo; así se comprende mejor el contexto en el que se quiere jugar el juego de la profesión de fe. El mensaje que se quiere dar es el de una Iglesia que continúa con la misión salvadora de Cristo, en un mundo bastante desolado. Hay un discurso teológico, pero le falta un cuerpo social o individual.

Encontramos que el destacar las imágenes y contrastarlas con las descripciones de las "formas de vida propia de los latinoamericanos” nos permite comprender por qué se insiste en la misión salvadora y en la preferencia por los pobres. La identificación sugerida de Iglesia con Cuerpo de Cristo se contrapone a la descripción del panorama de una América Latina en la que hay que reconocer "los enormes sufrimientos infligidos a los pobladores de este Continente durante la época de la Conquista y la Colonización”16. "Hay que reconocer con toda verdad los abusos cometidos, debidos a la falta de amor de aquellas personas que no supieron ver en los indígenas hermanos e hijos del mismo Padre, Dios. También se reconoce el testimonio positivo de quienes, al vivir la plenitud del Evangelio han sido los testigos más cualificados de Jesucristo, como Rosa de Lima, Martín de Porres y Ezequiel Moreno, entre otros"17.

\footnotetext{
3 CELAM. Santo Domingo. Conclusiones. Bogotá, 1992, No.7-8, pp. 56-57.

14 DE CERTEAU, Michel. La fábula mística. México: Universidad Iberoamericana, 1993, p. 100.

Ibíd., p. 98.

CELAM, Op. Cit., No. 20, p. 61.

Ibíd., No. 20, pp. 61-62.
} 
Hasta aquí nos hemos fijado preferentemente en las imágenes, pero éstas, al ser contrastadas con las descripciones de la "forma de vida” propia de los latinoamericanos cobran nuevos sentidos. Ante la unidad que sugiere la imagen de la Iglesia como cuerpo de Cristo, se ensombrece más el panorama. Otra nueva imagen nos sugiere la cercanía que se debe tener con las comunidades; es la del Buen Pastor que conoce sus ovejas y es conocido por ellas ${ }^{18}$. Desde aquí se hacen propuestas para la acción de las personas consagradas y laicos comprometidos, una acción pastoral basada en el testimonio: "Nos proponemos organizar mejor una pastoral de acompañamiento y apoyo a quienes se encuentran en ambientes especialmente difíciles (...). Queremos conservar una presencia humilde y cercana en medio de nuestras comunidades, para que todos puedan sentir la misericordia de Dios. Queremos ser testigos de solidaridad con nuestros hermanos"19.

“Los hermanos”, sujetos de esta nueva evangelización hecha testimonio, pasan ante nuestros ojos como una procesión o desfile de tipos de personas diferentes: los adolescentes, los creyentes de otras religiones, los indiferentes, las mujeres, los que se han afiliado a sectas religiosas. Pero esta enumeración no es para poner en escenarios interlocutores condenables o para convencerlos con argumentos teóricos, sino para describir su situación y relacionarla con la actitud del Buen Pastor que busca la oveja perdida, o la del Padre que acoge con un abrazo al Hijo Pródigo. "Muchos jóvenes son víctimas del empobrecimiento y de la marginación social, de la falta de empleo y del subempleo, de una educación que no responde a las exigencias de sus vidas, del narcotráfico, de la guerrilla, de las pandillas, de la prostitución, del alcoholismo, de abusos sexuales; muchos viven adormecidos por la propaganda de los medios de comunicación social y alienados por imposiciones culturales y por el pragmatismo inmediatista que ha generado nuevos problemas en la maduración afectiva de los adolescentes y de los jóvenes. (...) Los adolescentes y los jóvenes están cargados de interrogantes vitales y presentan el desafío de tener un proyecto de vida personal y comunitario que dé sentido a sus vidas y así logren la realización de sus capacidades; manifiestan el desafío de ser acompañados en sus caminos de crecimiento en su fe y trabajo eclesial y preocupaciones”20. Pero no es sólo la imagen del Buen Pastor que busca la oveja perdida, sino también la imagen de $L a$ vid y los sarmientos lo que nos recuerda que la fe y la integración en comunidad en la Iglesia, en el cuerpo de Cristo, son fenómenos vitales, como el de adherirse el sarmiento a la vid para no secarse. Son además las alusiones a la Curación de la hija de Jairo o a la Resurrección del hijo de la viuda de Naím, las que nos ubican en esa red espiritual que une a los creyentes y los compromete a servir como vasos comunicantes de la savia de esa vid.

En este contexto, la forma como el discurso expresa hacia dónde se debe orientar la acción pastoral es reveladora, pues nos encontramos con un discurso centrado en la praxis.

La propuesta del segundo Wittgenstein de relacionar las imágenes con "las formas de vida” y que en la interpretación de Jean Greish exige del analista el esfuerzo por encontrar la gramática profunda, es decir, descubrir las reglas a partir del uso, constituye el espacio desde podemos comprender el juego. Imaginar un lenguaje quiere decir ima-

\footnotetext{
Ibíd., No.74, p. 86.

Ibíd., Nos. 74-75, pp. 86-87.

Ibíd., No.112, p. 101.
} 
ginar una forma de vida ${ }^{21}$. En la instrucción en una fe religiosa, la exposición viene a hacer la descripción del sistema de referencia y al mismo tiempo una exhortación. "Como si alguien me hiciera ver por un lado mi situación desesperada y por otra parte me presentara el instrumento de salvación, hasta que yo por mi propia voluntad me precipite hacia ello hasta apoderarme de él”22. La imagen religiosa, aunque sea muy primitiva e inadecuada al objeto representado, puede tener un modo de empleo que nos permite comprender su significación. Desde este horizonte de comprensión hemos seleccionado algunas expresiones y exhortaciones del Documento que creemos permiten descubrir esa gramática profunda, esa expresión del contexto real desde donde se han traído a cuento, para comprender mejor su sentido.

Así, escuchamos a los Obispos: "Nos duele ver cómo muchos de nuestros fieles no son capaces de comunicar a los demás la alegría de su fe. Jesucristo nos pide que seamos $L a$ sal de la tierra, La levadura en la masa y sin descuidar a los cercanos salir al encuentro de los que están alejados”23.

"Muchos hermanos tienen su puerta cerrada y por medio de nuestro testimonio Cristo está a su puerta y llama. El desafío consiste en entrar en diálogo de salvación con todos, un diálogo de carácter testimonial dentro del respeto a la persona e identidad cultural del interlocutor"24.

Describen la situación en Latinoamérica donde no sólo existen ya otras religiones, sino que la proliferación de las sectas ha adquiri- do proporciones dramáticas por su creciente proselitismo. Y aclaran que las "sectas son grupos religiosos que insisten en que sólo la fe en Jesucristo salva y la única base es la Sagrada Escritura, interpretada de manera personal y fundamentalista, por lo tanto con exclusión de la Iglesia, y la insistencia en la proximidad del fin del mundo y del Juicio próximo. Están marcadas por un moralismo riguroso, por reuniones de oración con un culto participativo y emotivo" 25 .

Esta descripción nos permite ver ciertos rasgos de la forma de ser y vivir de los pueblos latinoamericanos que se sienten necesitados de Dios como solucionador de sus problemas, tienden a ser crédulos y gustan de las reuniones familiares participativas y emotivas. Las sectas han venido ocupando el espacio vacío que la rutina y el lenguaje de la Iglesia Católica, no tan inculturados, han creado entre la Iglesia y sus fieles. No es falta de religiosidad, sino falta de pertenencia. Por eso se busca en este Documento más una expresión de testimonio, más praxis y que los ritos respondan de veras a las formas de vida de los creyentes.

Recordemos que para Wittgenstein el hombre es un ser ritual: "Expresamos nuestros sentimientos e ideas a través de ritos que compartimos con nuestro entorno y por eso son comprensibles dentro de él. Cada palabra tiene su tierra natal y sacarla de allí, extrapolarla a otra tierra es enajenarla”26.

Esta descripción de la situación religiosa en Latinoamérica exige una respuesta apropiada; por eso se insta a que "La Iglesia sea cada

\footnotetext{
${ }^{21}$ GREISCH, Jean. “La religión al'interieur des limites du simple langage”. En : Penser le religion. París: Institute Catholique du Paris, p. 365.

22 Ibíd., p. 370.

CELAM, Op. Cit., No. 131, p. 106.

Ibíd., No.136, p. 109.

Ibíd., No. 140, p. 110.

DURÁN, Vicente. Op. Cit., p. 241.
} 
vez más comunitaria y participativa y con comunidades eclesiales, grupos de familias, círculos bíblicos, movimientos y asociaciones eclesiales se vaya conformando cada vez más la parroquia como comunidad de comunidades”27. De tal manera que se promueva una liturgia viva, participativa y con proyección a la vida. Porque los creyentes son la sal de la tierra, y con esta imagen sintetiza el documento el mensaje evangelizador.

La segunda línea presentada por los Obispos es la denominada promoción humana. La promoción humana es una exigencia de la Nueva Evangelización: “el hombre que hay que evangelizar es un ser sujeto a los problemas sociales y económicos”28.

La noción de promoción humana teóricamente está construida en la Doctrina Social de la Iglesia que "es la enseñanza del Magisterio en la actuación del creyente en la tarea de transformar el mundo según el proyecto de Dios"29.

Al querer fundamentar, de alguna manera, en una ciencia social como es la antropología y en la teología la situación del hombre concreto, el tono del discurso cambia en esta segunda parte del Documento. Pasa de ser profesión de fe, plegaria y descripción del estado de los creyentes, a una presentación de situaciones socioeconómicas, contrastadas a la luz de la teología y de la Doctrina Social de la Iglesia. Ya no desfilan ante nuestros ojos los sujetos de la Evangelización sino —como temas- los núcleos problemáticos de la convivencia humana, bajo la denominación de "signos de los tiempos"30. Vamos a enumerarlos, para dar alguna idea de esta temática: derechos humanos, ecología, la tie- rra como don de Dios, empobrecimiento y solidaridad, el trabajo, la movilidad humana, el orden democrático, el nuevo orden económico, la integración latinoamericana y la familia.

No entraremos en la polémica de la pertinencia de dar razón de los compromisos de la fe desde los argumentos de las ciencias humanas, porque la orientación de nuestra reflexión se limita a la fuerza simbólica de las imágenes del lenguaje religioso y su relación con la gramática profunda, la gramática de Dios que les da sentido y las convierte en paradigma de actitudes y conducta.

Esta segunda parte, como se comprende por lo anterior, no es tan rica en imágenes como la primera, pero de todos modos podemos destacar las siguientes: la referencia al pasaje evangélico de la Multiplicación de los panes, a la parábola de El buen Samaritano y al episodio de Las bodas de Caná ${ }^{31}$. Los tres se relacionan con el contexto de salvación de los necesitados y los criterios según los cuales serán juzgados los comportamientos de los creyentes ("al final de los tiempos nos juzgará en el amor”): “Jesús ordenó a sus discípulos que repartieran el pan multiplicado a la muchedumbre necesitada, de modo que comieron todos y se saciaron. Curó a los enfermos, pasó la vida haciendo el bien. Al final de los tiempos nos juzgará en el amor”.

Jesús es el Buen Samaritano que encarna la caridad, y que no sólo se conmueve, sino que se transforma en ayuda eficaz. Su acción está motivada por la dignidad de todo hombre, cuyo fundamento está en Jesucristo mismo como Verbo creador, encarnado. Como se-

\footnotetext{
CELAM. Op. Cit., No. 142, p. 111.

Ibíd., No. 157, p. 117.

Ibídem.

Ibíd., Nos. 163-164, p. 119.

Ibíd., Nos. 159 y 163, pp. 118-119.
} 
ñalaba Gaudium et Spes: "el misterio del hombre sólo se esclarece en el misterio del Verbo encarnado. (...) La solidaridad cristiana por ello es ciertamente servicio a los necesitados, pero sobretodo es fidelidad a Dios. Esto fundamenta lo íntimo de la relación entre evangelización y promoción humana"32. La fe implica obrar y este es un argumento práctico: Así, el Discurso prosigue en este tono: "Nuestra fe en el Dios de Jesucristo y el amor a los hermanos tiene que traducirse en obra concretas. (...) Esta preocupación de coherencia entre la fe y la vida ha estado siempre presente en las comunidades cristianas. Ya el Apóstol Santiago escribía: “¿de qué sirve, hermanos míos que alguien diga 'tengo fe', si no tiene obras? ¿Acaso podrá salvarle la fe? Si un hermano o una hermana están desnudos y carecen del sustento diario, y alguno de vosotros les dice 'idos en paz, calentaos y hartaos', pero no les dais lo necesario para el cuerpo ¿de qué sirve? Así también la fe, si no tiene obras, está realmente muerta”33.

La imagen de Las bodas de Caná refuerza la fe y la esperanza con la figura de María como la mujer solícita ante la necesidad surgida. "Es modelo y figura de la Iglesia frente a toda forma de necesidad humana" ${ }^{34}$.

La gramática profunda está dada por ese contexto de la caridad cristiana, por la que cada uno de los creyentes es responsable por su hermano y especialmente por el necesitado, y para cumplir esta tarea tiene la fuerza de pertenecer a la Iglesia, Cuepo Místico de Cristo, presencia viva de Jesús que camina a nuestro lado, y Madre, como María, que refuerza nuestra esperanza y nuestras accio- nes. Esta gramática profunda evangélica es lo que permite a los Obispos Latinoamericanos decidirse por la "opción por los pobres y necesitados".

Otro contexto es el que se describe en los temas enumerados anteriormente. Descripción realizada en términos de las ciencias sociales. Percibimos algo así como una encarnación más del Verbo en las categorías culturales de nuestro tiempo, para mostrar cuán necesitadas están la mayoría de las personas en Latinoamérica y cuán pertinente es privilegiar la opción por los pobres.

En la tercera línea presenta la tarea de una evangelización inculturada.

La imagen central es la del Cenáculo y la Venida del Espíritu Santo, imagen ubicada en el contexto del mandato evangelizador que pretende llegar a toda cultura. Manifiesta también la diversidad cultural de los fieles, cuando oían hablar a los apóstoles, cada uno en su propia lengua ${ }^{35}$.

El contexto de esta inculturación es el compromiso cristiano. Se trata de ser consecuentes con lo que ya se profesa, la Iglesia como cuerpo de Cristo, que promueve lo auténticamente humano, que nos compromete a "situar el mensaje evangélico en la base de su pensar, en sus principios fundamentales de vida, en sus criterios de juicio, en sus normas de acción, y de allí se proyecta en el ethos del pueblo (...) en sus instituciones y en todas sus estructuras" ${ }^{\prime 6}$.

Aquí predomina un lenguaje lleno de juicios de valor y de presupuestos filosóficos implícitos. Se fundamenta más en la teología, y

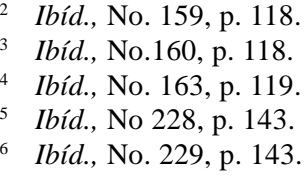


las imágenes evangélicas que eran el hilo conductor de nuestro análisis desaparecen del discurso.

El documento da un tratamiento especial a dos culturas vivas en América Latina y el Caribe, dos culturas que todavía se consideran como minorías étnicas, la afroamericana y la indígena. Relaciona la noción de inculturación con la encarnación del Verbo y con la muerte de Jesús para salvarnos a todos desde "la debilidad”. Predomina la analogía entre la encarnación y la presencia cristiana en el contexto sociocultural e histórico de los pueblos. Esta inculturación “es un proceso conducido desde el Evangelio hasta el interior de cada pueblo y comunidad con la mediación del lenguaje y de los símbolos comprensibles y apropiados a juicio de la Iglesia"37. Sin embargo, aunque el Documento propone la inculturación, todavía se percibe en él que la descripción de las “formas de vida” y “cosmovisiones” de otras culturas se sigue haciendo con la mirada que juzga desde fuera.

Se consideran también bajo la noción de cultura las nuevas formas urbanas de vivir y el fenómeno de los medios de comunicación.

Al avanzar en el análisis del Documento, se acentúa en nosotros la impresión de que el discurso retrocede en cuanto a su forma viva de presentar a Jesucristo, hoy, mañana y siempre, pues regresa a los discursos teóricos, en los cuales lo que estimula la praxis es la argumentación más que la fuerza de las imágenes religiosas.
En conclusión: desde el enfoque del segundo Wittgenstein y sus categorías de análisis de juego del lenguaje, gramática profunda, imagen, forma de vida y creencia religiosa, la primera parte del Documento de Santo Domingo presenta una riqueza muy grande que permite a los creyentes en Cristo y en la Iglesia Católica dar sentido a su fe y convertirla en praxis de una forma viva y concreta. La promoción humana y la inculturación vienen a ser consecuencias prácticas de esta fe y de este compromiso, y permiten contextualizar mejor el enraizamiento en la situación espacio-temporal de diferentes culturas.

Aunque pobre en imágenes en las últimas partes, el Discurso nos permite comprender mejor el por qué de ese giro pastoral de los Obispos Latinoamericanos que privilegia la opción por los pobres.

Podríamos decir que el discurso en su primera parte está dirigido a los creyentes latinoamericanos. $\mathrm{Y}$ en su segunda y tercera parte parece estar dirigido a los pastores y laicos más comprometidos.

Finalmente, consideramos que valió la pena haber hecho este ejercicio de lectura y haber intentado su análisis desde un nuevo enfoque, porque hemos podido constatar que, en últimas, hoy en los discursos religiosos lo que más convence es la firmeza de la fe de los creyentes y la fuerza del testimonio de la forma de vida que ella anima.

${ }^{37}$ Ibíd., No. 243, p. 148. 